\title{
The effectiveness of newly developed written asthma action plan in improvement of asthma outcome in children
}

\author{
Kingthong Lakupoch, Wiparat Manuyakorn, Aroonwan Preutthipan, Harutai Kamalaporn
}

\begin{abstract}
Background: Providing asthma education about controller medication use and appropriate management of asthma exacerbation are the keys to improving the disease outcome. Many asthma guidelines recommend that physicians provide written asthma action plan (WAAP) to all of their asthmatic patients. However, the benefit of WAAP is unclear. Thus, we have created a new WAAP which is simplified in Thai and more user friendly.
\end{abstract}

Objective: To determine the effectiveness of the newly developed asthma action plan in management of children with asthma.

Methods: Asthmatic children who meet inclusion criteria all received the WAAP and they were followed up for 6 months with measurement of outcome variables, such as asthma exacerbation that required emergency room visit, unscheduled OPD visit, admission and school absence in order to compare with the past 6 months before receiving the WAAP.

Results: The analyzed outcomes of forty-nine children show significantly reduced emergency room visit (P-value 0.005), unscheduled OPD visit (P-value 0.046), admission days (P-value 0.026) and school absence days (P-value 0.022). Well controlled group and mild severity group were not the factors that contribute to decreased emergency room visit but step up therapy may be the co-factor to decreased ER visit.

Conclusions: The results of this study suggest that the provision of newly developed WAAP is useful for improving self- care of asthma patients and reducing asthma exacerbation.

Keywords: Asthma children, asthma exacerbation, effectiveness, emergency room visit, written asthma action plan

\section{From:}

Department of Pediatrics, Faculty of Medicine, Ramathibodi Hospital,

Mahidol University, Bangkok, Thailand
Corresponding author:

Harutai Kamalaporn

270 Rama VI road, Thung Phaya Thai, Ratchathewi, Bangkok 10400, Thailand

Email: doctoroom@yahoo.com

\section{Introduction}

Asthma is one of the most common chronic diseases in childhood. Its prevalence has been increasing worldwide causing socioeconomic consequences. A cross-sectional study in Thai elementary school students in Bangkok reported that less than half of students with current asthma achieved control and the overall controller medication used was only $26.7 \%{ }^{1}$ Therefore asthma exacerbation is not uncommon. Many asthma guidelines such as GINA and Thai asthma guidelines recommend physicians to provide a "written asthma action plan" (WAAP) to all children with asthma. ${ }^{2}$ The meta-analysis in 2008 showed that information about asthma exacerbation and appropriate management can reduce the mean number of hospitalizations and emergency room (ER) visit. ${ }^{3}$
WAAP educates patients about warning signs and symptoms of an oncoming asthma episode, how to regularly use the peak flow meter for self-monitoring and how to realize what to do in a breathing emergency. It is controversial whether WAAP play any additional role in improvement of asthma outcomes over the routine asthma education, especially in children..$^{4-9}$

In Thailand, WAAP for children is not popular. The survey in pediatric pulmonary and allergy staffs and fellows at Ramathibodi Hospital, Mahidol University reported that the reasons for infrequent use of WAAP included too time -consuming for doctors and difficult for parents to understand or follow the instructions. Actually, there is no specific format of WAAP worldwide. Only red, yellow, and green colors 
mimicking the traffic lights are recommended. Thus, we created a new WAAP which is composed of colorful pictures of children in three different levels of comfort along with peak flow level and symptoms of asthma. In adults, $60 \%$ of asthma patients overestimate their asthma control, this may lead to incorrect management according to WAAP. ${ }^{10}$ Therefore we use peak flow level in our action plan as an objective measurement to enhance the accuracy of asthma assessment. In addition, we inserted colorful pictures of all asthma medications and devices available in our institute adjacent to the simplified instructions concordant with standard asthma guidelines in Thai. The distinctive points of our new WAAP were its objective measurement by using peak flow level, the pictures of all medications in an easy-to-understand format, and a pre-set of instructions in Thai therefore physicians can complete the WAAP in a few minutes. Thus, we hope this WAAP would be more user friendly for both physicians and caregivers.

Our study aims to prove the effectiveness of the new WAAP in children in terms of improving self-management resulting in better asthma outcomes defined by decrement rate of ER visits, unscheduled OPD visits, hospitalization and school absence due to acute asthmatic attack.

\section{Methods}

We conducted a prospective study of children aged 5-18 years with a diagnosis of asthma who had been followed up in pediatric pulmonary and allergy subspecialty clinics in Ramathibodi Hospital from March 2015 - October 2016. The WAAP was developed and validated among pediatric chest and allergy fellows and staffs before starting to use in both clinics. For the caregivers and patient, we verbally validated the understanding of WAAP with them when recruited and every three months' time when follow up in clinics.

We recruited children who were able to perform peak flow meter and had used inhaled corticosteroid for at least 3 months prior to participation in the research study in order to ensure the correct technique of medications and devices usage. Children who developed asthma exacerbation requiring hospitalization in the past 1 month or had either cardiovascular diseases or chronic lung diseases were excluded. The informed consents were obtained from parents.

Each enrolled children received a questionnaire about baseline characteristics and history of asthma exacerbation in the previous 6 months. The newly developed WAAP was then given along with the peak flow meter.

At enrollment, the responsible physicians had to teach and confirm that the patients were able to use the peak flow meter properly. The personal best peak flow data was recorded in the WAAP and used for determining the level of severity of asthma. The physicians emphasized the patients to use controller regularly and monitor their symptoms by using peak flow twice daily as shown in WAAP. Their own symptoms were recorded. Physicians and caregivers then reviewed the WAAP together to confirm that the caregivers understand the plan for self- management for each severity level.

The outcome variables were then collected from the medical record and caregivers' interviews at the $3^{\text {rd }}$ and $6^{\text {th }}$ month of pulmonary/allergy clinic visits respectively.
Primary outcome was the number of ER visits. Secondary outcomes were number of unscheduled OPD visits, number of admission days due to acute asthmatic attack and the number of school absence days. The definition of unscheduled OPD visits was the children with mild asthma exacerbation who chose to visit the pediatricians at outpatient department

without any appointment during working hours rather than went to ER to receive asthma management such as nebulized bronchodilator, and/or asthma medical adjustment. The definition of school absence was the children who had symptoms of asthma exacerbation and could not go to school. When 6 months follow up was completed, we evaluated the patient's WAAP adherence with a questionnaire asking about using WAAP and patients/caregivers' satisfaction.

In addition, we identified the possible factors that might confound the improvement of asthma outcome such as level of controlled, severity of asthma and step up therapy. The definition of step up therapy is the increased asthma medications following the GINA guidelines such as increased inhaled corticosteroid dosage, added on montelukast and/or long acting beta 2 agonist in 6 months after receiving WAAP.

This study was approved by the committee on Human rights related to research involving human subjects, Faculty of Medicine, Ramathibodi Hospital, Mahidol University.

Study design was a prospective cohort. Categorical variables were reported as counts and compared using McNemar and Fisher exact test, as appropriate. Total ranges for some variables were provided as well. Continuous variables were analyzed by using Wilcoxon sign rank test. Data was analyzed by SPSS software version 17. A p-value of $<0.05$ was considered to be statistically significant.

\section{Results}

Fifty two children with asthma from pediatric pulmonary and allergy clinics at Ramathibodi Hospital were enrolled. Two of them were lost follow up, and one child was treated with immunotherapy which was a co-intervention. Of the 52 children, 49 (94\%) completed the study and were included in the analysis.

Most of the children were male and two-thirds of them were 5-11 years old. Mean duration of having been diagnosed with asthma was 5.5 years prior to participating in this study. Most of the children (38 of $52 ; 78 \%$ ) had moderate to severe persistent asthma as defined by dosage and type of inhaled corticosteroids used. However, most of them were well- controlled as defined by no asthma symptoms in the previous 4 weeks before enrollment. Allergic rhinitis was the most common comorbid and $37 \%$ of children had positive skin prick test as shown in Table 1.

\section{Primary outcome \\ Emergency room visit}

The total number of ER visit before receiving WAAP was 18 visits. After receiving WAAP, it was reduced to 3 visits. This shows a significant decrease in number of ER visits ( $\mathrm{p}$-value $=$ $0.005)$.

The number of children who had ER visits was also significantly decreased after using WAAP. In the previous 6 
Table 1. Baseline characteristics of the patients at enrolment

\begin{tabular}{|rr}
\hline Baseline Characteristics & $\mathbf{N}=\mathbf{4 9}$ \\
\hline $\begin{array}{l}\text { Gender } \\
\text { male }\end{array}$ & $36(73 \%)$ \\
female & $13(27 \%)$ \\
\hline Age & \\
\hline $5-11$ year-old & $32(65 \%)$ \\
12-18 year-old & $17(35 \%)$ \\
\hline Mean weight (kg) & $39(19)$ \\
\hline Mean Height (cm) & $140(16)$ \\
\hline Mean Duration of asthma (years) & \\
\hline Control of asthma & $5.5(3.6)$ \\
Controlled & \\
Partly controlled & $38(78 \%)$ \\
Uncontrolled & $9(18 \%)$ \\
\hline Severity of asthma & $2(4 \%)$ \\
Mild persistent & \\
Moderate persistent & $11(22 \%)$ \\
Severe persistent & $23(47 \%)$ \\
\hline Underlying disease & $15(31 \%)$ \\
Allergic rhinitis & \\
Chronic sinusitis & \\
Food allergy & $38(77 \%)$ \\
GERD & $1(2 \%)$ \\
OSA & $1(2 \%)$ \\
Obesity & $4(8 \%)$ \\
SPT positive & $2(4 \%)$ \\
\hline & $4(8 \%)$ \\
\hline
\end{tabular}

months, reporting 13 children had a total of 18 ER visits, and after using WAAP, only 3 children had a total of 3 ER visits $(\mathrm{p}$-value $=0.006)$ (Table 2$)$.

Table 2. Comparison of outcome variables before and after receiving WAAP

\begin{tabular}{|c|c|c|c|}
\hline & $\begin{array}{l}\text { Before } \\
(\mathrm{N}=49)\end{array}$ & $\begin{array}{c}\text { After } \\
(\mathrm{N}=49)\end{array}$ & $p$-value \\
\hline Total number of ER visits & 18 & 3 & $\mathrm{~N} / \mathrm{A}$ \\
\hline Number of patients had ER visits & $13(26 \%)$ & $3(6 \%)$ & $0.006^{*}$ \\
\hline Total number of OPD visits & 4 & 0 & N/A \\
\hline Number of patients had OPD visits & $4(8 \%)$ & 0 & N/A \\
\hline Total number of admission days & 17 & 0 & $\mathrm{~N} / \mathrm{A}$ \\
\hline Number of patients had admission & $6(12 \%)$ & 0 & $\mathrm{~N} / \mathrm{A}$ \\
\hline Total number of school absence days & 55 & 12 & N/A \\
\hline $\begin{array}{l}\text { Number of patients had school } \\
\text { absence }\end{array}$ & $10(20 \%)$ & $5(10 \%)$ & $0.227^{\star}$ \\
\hline
\end{tabular}

P-value calculated from McNemar test*

Sixteen of forty-nine children (33\%) had symptoms/peak flow level in yellow zone. Thirteen of sixteen children (81\%) used reliever and followed the suggestions in yellow zone. All of them got better after self-management and did not have to visit the emergency room(ER). All three exacerbated children ( 3 of $16 ; 19 \%$ ) did not follow the instruction in yellow zone had to go to ER.

\section{Secondary outcomes}

Unscheduled OPD visit, Hospitalizations and School Absence

There was a significant decrease in the number of unscheduled OPD visit ( $\mathrm{p}$-value $=0.046$ ), the number of days of admission ( $p$-value $=0.026$ ) and also a significant decrease in the number of days of school absence ( $\mathrm{p}$-value $=0.022$ ).

Four children had unscheduled OPD visits before receiving WAAP, but no children had unscheduled OPD visit after receiving WAAP. Six children had hospital admissions before receiving WAAP but no children had hospital admissions after receiving WAAP (Table 2 ).

Ten children had school absence before receiving WAAP. However, only 5 children had school absence after receiving WAAP, but there was no statistical significance ( $\mathrm{p}$-value 0.227 ) (Table 2).

Factors contributive to decreased ER visit

The possible factors that could affect decrement of asthma exacerbation in 6 months after using WAAP are, for example, the children in well controlled, mild severity group, step up therapy group or children who enrolled in the low season of asthma exacerbation (August to January). These groups were then analyzed in their respective subgroups. There was a significant improvement in the number of ER visits in a step up therapy group (p-value 0.009). Other factors have no statistically significant difference between groups (Table 3).

Table 3. Possible factors affecting decreased number of patients with ER visits 6 months after using WAAP

\begin{tabular}{|c|c|c|c|}
\hline \multirow[t]{2}{*}{ Factor } & \multicolumn{2}{|c|}{ ER visit } & \multirow[t]{2}{*}{$p$-value } \\
\hline & $\begin{array}{c}\text { decreased } \\
(\mathrm{N}=11)\end{array}$ & $\begin{array}{l}\text { unchanged }^{*} \\
\qquad(\mathrm{~N}=38)\end{array}$ & \\
\hline $\begin{array}{l}\text { Level of controlled } \\
\text { - Well controlled } \\
\text { - Partly/Uncontrolled }\end{array}$ & $\begin{array}{l}6(16 \%) \\
5(45 \%)\end{array}$ & $\begin{array}{c}32(84 \%) \\
6(55 \%)\end{array}$ & 0.094 \\
\hline $\begin{array}{l}\text { Severity of asthma } \\
\text { - Mild } \\
\text { - Moderate/severe }\end{array}$ & $\begin{array}{c}0 \\
11(29 \%)\end{array}$ & $\begin{array}{c}11(100 \%) \\
27(71 \%)\end{array}$ & 0.050 \\
\hline $\begin{array}{l}\text { Medication } \\
\text { - Step up } \\
\text { - No step up }\end{array}$ & $\begin{array}{l}5(63 \%) \\
6(15 \%)\end{array}$ & $\begin{array}{c}3(37 \%) \\
35(85 \%)\end{array}$ & 0.009 \\
\hline $\begin{array}{l}\text { Season } \\
\text { - August-January } \\
\text { - February-July }\end{array}$ & $\begin{array}{l}5(17 \%) \\
6(32 \%)\end{array}$ & $\begin{array}{l}25(83 \%) \\
13(68 \%)\end{array}$ & 0.298 \\
\hline
\end{tabular}

${ }^{\star}$ Unchanged: included more ER visits in 6 months after using WAAP $P$-value calculated from McNemar test*

\section{WAAP adherence and satisfaction}

At the end of the study, 46 of 49 parents (94\%) answered the questionnaire about regularly using WAAP and family satisfaction. Eighty-five percent of parents usually used the WAAP. Eighty-seven percent of parents had a positive feeling of having and using WAAP. Eighty-three percent of them felt more confidence in self-management of their children's asthma symptoms (Table 4). About the physicians, 13 pediatric pulmonary and allergy staffs and fellows who used this WAAP reported that new WAAP had easy format to use (Score 5/5: 
62\%, 4/5: 38\%) and most of them (69\%) could complete this WAAP within 5-10 minutes.

Table 4. Parent and family evaluation after using WAAP.

\begin{tabular}{|c|c|c|c|c|c|}
\hline & \multicolumn{5}{|c|}{ Level } \\
\hline & 5 & 4 & 3 & 2 & 1 \\
\hline $\begin{array}{l}\text { Regularity of using } \\
\text { WAAP }(\mathrm{N}=46)\end{array}$ & $\begin{array}{c}29 \\
(63 \%)\end{array}$ & $\begin{array}{c}10 \\
(22 \%)\end{array}$ & $\begin{array}{c}6 \\
(13 \%)\end{array}$ & 0 & $\begin{array}{c}1 \\
(2 \%)\end{array}$ \\
\hline $\begin{array}{l}\text { Regularity of using ICS } \\
\left(\mathrm{N}=25^{¥}\right)\end{array}$ & $\begin{array}{c}7 \\
(15 \%)\end{array}$ & & $\begin{array}{c}13 \\
(74 \%)\end{array}$ & $\begin{array}{c}5 \\
(11 \%)\end{array}$ & 0 \\
\hline $\begin{array}{l}\text { Confidence of asthma } \\
\text { self- management }(\mathrm{N}=46)\end{array}$ & $\begin{array}{c}38 \\
(83 \%)\end{array}$ & $\begin{array}{c}6 \\
(13 \%)\end{array}$ & $\begin{array}{c}2 \\
(4 \%)\end{array}$ & 0 & 0 \\
\hline $\begin{array}{l}\text { Understanding of asthma } \\
\text { severity and proper } \\
\text { management }(\mathrm{N}=45)\end{array}$ & $\begin{array}{c}29 \\
(61 \%)\end{array}$ & $\begin{array}{c}16 \\
(39 \%)\end{array}$ & 0 & 0 & 0 \\
\hline $\begin{array}{l}\text { Satisfaction of using } \\
\text { WAAP }(\mathrm{N}=46)\end{array}$ & $\begin{array}{c}40 \\
(87 \%)\end{array}$ & $\begin{array}{c}5 \\
(11 \%)\end{array}$ & $\begin{array}{c}1 \\
(2 \%)\end{array}$ & 0 & 0 \\
\hline
\end{tabular}

Note Level 5 : degree of maximum, level 1: degree of minimum

$¥:$ the patients who already regular using ICS did not answer this question

\section{Discussion}

The majority of our population were school-aged children with moderate to severe asthma, though most of them were well controlled. At 6 months after using our newly developed WAAP, the number of children who had ER visits was significantly decreased. The result is partly consistent with the previous studies., ${ }^{5,7}$

GINA 2015-2017 guidelines recommend written asthma action plan to all patients with asthma to guide their self -management efforts. Self- monitoring with peak flow meter is recommended in "moderate to severe asthma" patients who need prescribed daily medication for symptom control. WAAP reminds daily use of controllers, information on how to recognize and handle worsening asthma, and when to seek for an emergency health care.

Daily peak expiratory flow monitoring can be used to assess the severity of asthma, response to medication, and detect early stages of asthma exacerbations. Patients become actively involved in managing their asthma. This may result in improved health outcomes and better asthma quality of life, especially in those who have a history of severe exacerbations or patients who poorly perceive airflow obstruction and worsening asthma. ${ }^{11}$

In 2009, Tatiana Espinoza-Palma et al studied 77 children who got admitted due to acute asthmatic attack. ${ }^{5}$ This randomized controlled trial showed that asthma exacerbations, emergency visits hospitalizations significantly decreased after using asthma action plan but there was no significant difference from controlled group.

In 2013, Su Sien Wong et al studied 80 children aged 6-17 years old, most of whom were partly/uncontrolled asthma. ${ }^{7}$ This randomized controlled trial showed significant improvement of asthma controlled test score before and after receiving action plan. However, there was no significant difference from controlled group.
Although providing written asthma action plan is recommended in many asthma guidelines, previous studies in the last decade showed that adding a WAAP can improve asthma outcome but no better than standard treatment and education..$^{5-8}$ Only one study in 2005 by Agrawal et al showed that adding WAAP can improve asthma outcome when compared with controlled group. ${ }^{4}$ Noticeably both Agrawal et al and our study, all of the children applied the peak flow-based asthma action plan but other studies partially applied symptom-based asthma action plan. As a result, peak flow meter may be an important factor that should be tested in further studies.

WAAP also serve as a linking tool of coordination across multiple caregivers such as school nurses, and general practitioners in different clinics/hospitals. Using easy and instructive WAAP, children with asthma could receive appropriate management, especially while having acute asthmatic attack. However, symptom perception of airway obstruction is generally poor for asthmatic children and their parents. A peak flow meter is a simple device that can detect airway obstruction since early stages of acute asthma episodes. A drop in peak expiratory flow is an objective measurements of airway obstruction which can alert the patients and caregivers in starting to manage acute asthmatic attack. ${ }^{12-14}$ In many countries, peak flow meters are provided along with WAAP for asthmatic patients without any expense. Unfortunately, they are not covered by the Thai National Health Insurance. A pilot study in 2011 revealed that the annual direct medical cost of exacerbation group is as high as twice of non-exacerbation group (14,232 Baht v.s. 7,416 Baht, $\mathrm{p}=0.02) .{ }^{15}$ Our study demonstrated that using peak flow meter along with WAAP was feasible, useful and practical in children. The cost-effectiveness study should be done to explore whether using peak flow meter with WAAP is beneficial in decrement of asthma exacerbations. If this is the case, it should be considered to get the peak flow meters covered by Thai National Health Insurance in the future.

Although there was a systematic review in 2008 that included 4 studies between 1990-2004 that showed that symptom-based asthma action plan could reduce acute care visit more than peak flow-based plan. ${ }^{16}$

In addition, Agrawal et al and our study had been done in developing countries which have limited number of physicians and nurse practitioners. ${ }^{3}$ Our finding is similar to a study in 2012 when peak flow meter was used along with WAAP with favorable outcome in quality of life. Peak flow meter may be an important factor of this distinguish outcome in children. It may increase children's awareness of their asthma symptoms that led to early intervention, resulting in improved symptom control. ${ }^{11}$ Current medical practice with numerous patients may not be able to provide complete asthma education for every children and caregivers in a timely manner. Therefore WAAP with complete information may be a helpful tool to improve asthma outcome in this setting.

Characteristics of WAAP was one of the important factors that lead to improvement of asthma outcome. ${ }^{17-19}$ In 2008, Matthew A. Rank et al defined the characteristics of poor and good WAAP and synthesized practical suggestions for formulating an effective and efficient WAAP. ${ }^{19}$ For example, 
WAAP should have only 2-4 clearly specific action points, appropriate language, etc. The distinctive points of our newly developed WAAP are using pictures of asthma symptoms along with simple format in Thai, colorful pictures of all available medications and devices which are more understandable. It is also user-friendly. The physicians can complete it within 5 minutes. Simplified WAAP may be the tool that can remind the patients to use controller, monitor themselves regularly and become more confident to use reliever when needed. These may be the contributing factors of improved asthma outcomes in our study.

Because some confounding factors such as the well -controlled of asthma, mild severity and step up therapy could affect decrement rate of ER visits, therefore subgroup analysis was done (Table 3 ). We found that the number of children with ER visit in 6 months after using WAAP had no significant difference between well-controlled V.S. partly/uncontrolled group ( $\mathrm{p}$-value $=0.094)$, mild V.S. moderate to severe persistent group ( $\mathrm{p}$-value $=0.05)$. But there was a significant decrease in number of children with ER visits in a step up therapy group compared with non-step up therapy group $(p=0.009)$. Therefore decreasing of ER visit from outcome of this study may be from newly developed WAAP and/or step up therapy, but we could not conclude which one was the most effective. We realized that stepping up of asthma medications adjusted by asthma severity level can definitely improve the disease outcome if the patients really use it. We believed that patient's compliance is the key factor. Our newly developed WAAP may play a role of a friendly reminder. It has both subjective and objective measurements of self- monitoring by using symptom-based and the peak flow meter value. We hope it can enhance the patients' awareness leading to better compliance and adherence to asthma guidelines.

\section{Limitation of studies}

Our study had no controlled group. Also some factor, such as seasonal variation of enrollment period may contribute some bias. In addition, we compared the number of outcome variables from previous 6 months that could be the recall bias.

\section{Conclusion}

Our newly developed written asthma action plan was efficient in improvement of asthma outcome in children determined by significant decrement of ER visits, unscheduled OPD visit, admission days and school absence days.

\section{Acknowledgement}

The authors would like to express gratitude to the Faculty of Medicine, Ramathibodi Hospital's research grant, and we appreciated all supports and suggestions from the pulmonary and allergy staffs, fellows and nurses.

\section{References}

1. Wanlapakorn N, Sritippayawan S, Deerojanawong J. Prevalence of asthma, level of control and factors associated with asthma control in Thai elementary school students in Bangkok. Asian Pac J Allergy Immunol. 2014;32:287-92.

2. Global Initiative for Asthma. Global strategy for asthma management and prevention 2016 [Internet]. [place unknown]: Global Initiative for Asthma; c2016 [cited 2017 Feb 3]. Available from: http:/ginasthma.org/2016-gina -report-global-strategy-for-asthma-magement-and-prevention/.

3. Coffman JM, Cabana MD, Halpin HA, Yelin EH. Effects of asthma education on children's use of acute care services: a meta-analysis. Pediatrics. 2008;121(3):575-86.

4. Agrawal SK, Singh M, Mathew JL, Malhi P. Efficacy of an individualized written home-management plan in the control of moderate persistent asthma: a randomized, controlled trial. Acta Paediatr. 2005;94:1742-6.

5. Espinoza-Palma T, Zamorano A, Arancibia F, Bustos MF, Silva MJ, Cardenas C, et al. Effectiveness of asthma education with and without a self-management plan in hospitalized children. J Asthma. 2009;46:906-10.

6. Sunshine J, Song L, Krieger J. Written action plan use in inner-city children: is it independently associated with improved asthma outcomes? Ann Allergy Asthma Immunol. 2011;107:207-13.

7. Wong SS, Nathan AM, de Bruyne J, Zaki R, Mohd Tahir SZ. Does a written asthma action plan reduce unscheduled doctor visits in children? Indian J Pediatr. 2013;80:590-5.

8. Sheares BJ, Mellins RB, Dimango E, Serebrisky D, Zhang Y, Bye MR, et al. Do patients of subspecialist physicians benefit from written asthma action plans? Am J Respir Crit Care Med. 2015;191:1374-83.

9. John M. Kelso. Do written asthma action plans improve outcomes? Pediatric Allergy Immunol Pulmonol. 2016;29(1):2-5.

10. Boonsawat W, Thompson PJ, Zaeoui U, Samosorn C, Faruqi R, Poonnoi P. Survey of asthma management in Thailand-the asthma insight and management study. Asian Pac J Allergy Immunol. 2015;33:14-20.

11. Burkhart PV, Rayens MK, Oakley MG. Effect of peak flow monitoring on child asthma quality of life. J Pediatr Nurs. 2012 Feb;27(1):18-25.

12. Kotses H, Harver A, Humphries CT. Home monitoring in asthma self -management. J Asthma. 2006;43:649-55.

13. Harver A, Humphries CT, Kotses H. Do asthma patients prefer to monitor symptoms or peak flow? J Asthma. 2009;46:940-3.

14. Yoos HL, Kitzman H, Mc Mullen A, Sidora K. Symptom perception in childhood asthma: How accurate are children and their parents? J Asthma. 2003;40(1):27-39.

15. Puranitee P, Kamchaisatien W, Manuyakorn W, Vilaiyuk S, Laecha O, Pattanaprateep O, et al. Direct medical cost of Thai pediatric asthma management: a pilot study. Asian Pac J Allergy Immunol. 2015;33:296-300.

16. Zemek RL, Bhogal SK, Ducharme F. Systematic review of randomized controlled trials examining written action plans in children. Arch Pediatr Adolesc Med. 2008;162:157-63.

17. Yin HS, Gupta RS. Readability, Suitability, and characteristics of asthma action plans: examination of factors that may impair understanding. Pediatrics. 2013;131;e116.

18. Raveed K, Rohan M. Effectiveness of personalized written asthma action plans in the management of children with partly controlled asthma in Trinidad: a randomized controlled trial. J Trop Ped. 2014;60(1):17-26.

19. Rank MA, Volcheck GW, Li JT, Patel AM, Lim KG. Formulating an effective and efficient written asthma action plan. Mayo Clin Proc. 2008;83(11): 1263-70. 